\title{
Climate change perception and adaptation among indigenous farmers : A study on Thamis of Dolkha
}

\author{
B. J. Thapa ${ }^{1}$
}

\begin{abstract}
Anthropogenic climate change is perceived as one of the most threatening global environmental issues today. A common finding in the past researches is that most of the vulnerable communities affected by the changing climate are the indigenous ones living in rural parts of the world, mostly from the developing nations. These indigenous communities have a close relation with their surrounding environments which have provided them a vast knowledge and clues about the micro-climatic conditions in their surroundings. These clues shape their perceptions and adaptation practices. This research was conducted on the indigenous Thami Community of Nepal focusing on their perceptions towards changing climate and their adaptation practices in congruence with their local and indigenous knowledge about their environment. As Thamis are mostly reliant on subsistence agricultural farming for their livelihood, this study mainly focuses on the impacts of climate change on agriculture practices of Thami Community of Dolakha district. In this study it was found that the practices of Thamis were severely affected by the changing environmental conditions. The farmers perceived changes in temperatures, precipitation and extreme weather events, and interpreted those as per their understanding of their surroundings.
\end{abstract}

Keywords : Agriculture, community, people, production, vulnerability

$\mathrm{I}$ $\mathrm{n}$ the past century, global warming has been one of the major reasons for climate change. Statistically speaking, $95 \%$ of the observed climatic changes is human induced, most of which is due to excessive greenhouse gases (GHG) emissions (Pachauri et al., 2014). These emissions are mainly driven by population size, economic activities, lifestyle, energy use, land use patterns, technology and climate policy that impact on different global natural systems.

Indigenous communities living in rural areas are among the most affected groups of people by climate change who bear the brunt of it all. Often, they are solely dependent on agricultural practices in small land holdings which make them even more vulnerable to environmental hazards. Furthermore, this situation is worsened due to illiteracy and limited understanding of the implications of climate change and its effects on the environment.
In these communities, their daily activities are guided by decades of experiences regarding their environment and the indigenous knowledge passed on through generations, which also shape their perceptions about their local environment. Thus, individual perceptions of the people living in these communities are important for gaining vital information in order to understand the changes in their local environment due to climate change.

Perceptions shape the ability to comprehend and react to environmental risks associated with natural hazards caused by the changing climate (Arbuckle et al., 2015). Based on these reactions, one can learn about complex issues and problems regarding environmental hazards, which can be essential in formulating plans and policies for adaptation practices. Overall, local perceptions help in understanding and addressing the multiple stresses and multi-faceted vulnerabilities due to

Jawalakhel, Lalitpur, Nepal. Email : thapabinayj@gmail.com 
the direct involvement and understanding of the local people in the affected surroundings (MoSTE, 2015).

Nepal is a least developed agrarian country where $65 \%$ of the population and $33 \%$ of the GDP are based on agriculture (MoAC, 2011). It is ranked as the $4^{\text {th }}$ country on the vulnerability index list in 2011 (Maplecroft, 2011). Most of the studies point out that climatic conditions of Nepal is changing at an alarming rate with an increase in average maximum temperature by $0.06{ }^{\circ} \mathrm{C}$ per annum since the past four decades. Despite having only $0.4 \%$ of the total global population responsible for 0.025 percent of the total GHGs emissions globally, Nepal is affected disproportionately by climate change (NAPA/ MoPE, 2010). Consequently, floods, landslides, intense rains, hailstorms, droughts, cold and heat waves and other climate-related hazards are regular phenomenon in the country (MoAC, 2011).

Agriculture is anticipated to be the most vulnerable sector because of low adaptive capacity of the poor farmers and their high dependency on climate-sensitive natural resources, such as water resources, forest products, soil and ecological systems. The strain of it all falls on the Nepalese farmers who are forced to alter traditional lifestyles, cultures and identities as a result of unpredictable climate changes. Likewise in the past, the status of the environment paralleled the perceptions and understanding of the indigenous people. The current altered and unpredictable state of the environment makes the acquired indigenous knowledge ineffective for adaptation to hazards in agriculture.

Primarily agrarian and skilled builders, Thamis are one of the most marginalized communities of Nepal. It is only recently that the Government of Nepal acknowledged their identity as a distinct ethnicity. Even so, they are dramatically affected by the changing climatic conditions, and are struggling to adapt to these impacts.

\section{Materials and methods}

\section{Research site}

The research was conducted in Bhimeshwor Municipality of Dolakha district of Province
No. 3, Nepal. The Bhimeshwor Municipality is situated between $27^{\circ} 44^{\prime} 33.57^{\prime \prime} \mathrm{N}$ and $27^{\circ} 36^{\prime}$ $45.38^{\prime \prime} \mathrm{N}$ latitudes and between $86^{\circ} 01^{\prime}$ 60.00" $\mathrm{E}$ and $85^{\circ} 57^{\prime} 36.02^{\prime \prime} \mathrm{E}$ longitudes (Fig.1). The municipality has been named after the very ancient and sacred Dolakha Bhimeshwor Temple. The region is bordered by Sun Koshi River on the west and Khimti Khola on the east. On the northeast side of the site lies the impressive Rolwaling Mountain range whereas peaks such as Gauri Shanker and Melungtse lie on the western side (GoN, 2017).

Two villages, viz. Topar and Lisapoto of Suspa were chosen as the research sites from the Bhimeswor Municipality. The climatic characteristics of these places coincide with that of the hilly regions of Nepal. The temperatures vary along with the altitudinal variation and geographical characteristics with lower valley regions having minimum temperature of approximately $3^{\circ} \mathrm{C}$ going up to $20^{\circ}-22^{\circ} \mathrm{C}$ maximum whereas the temperature remains around $0^{\circ} \mathrm{C}$ at the higher elevations. This region has a yearly rainfall of around 2000 $\mathrm{mm}$ (GoN, 2007). The research was conducted in August, 2017.

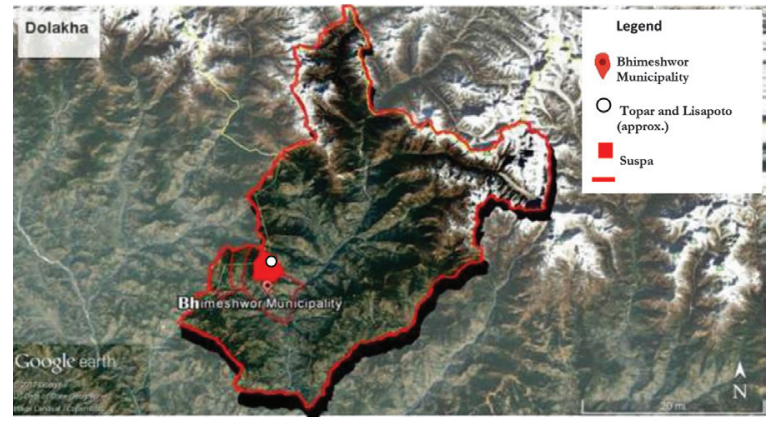

Source : Google Earth, GIS map

\section{Figure 1 : Location of Bhimeshwor Municipality in Dolakha district}

This study adopted mixed approach for data collection and analysis. To generalize and make the data more objective, a questionnaire survey of 100 households (HHs) was conducted. The questionnaire captured the socio-economic dimensions of the village, their perceptions concerning climate change and the practiced adaptation measures. Likewise, the primary data were collected through field observations, indepth interviews and focused group discussions (FGDs). The combination of both qualitative and 
quantitative methods yielded convergent findings which were based on Concurrent Triangulation Design (Figure 2).

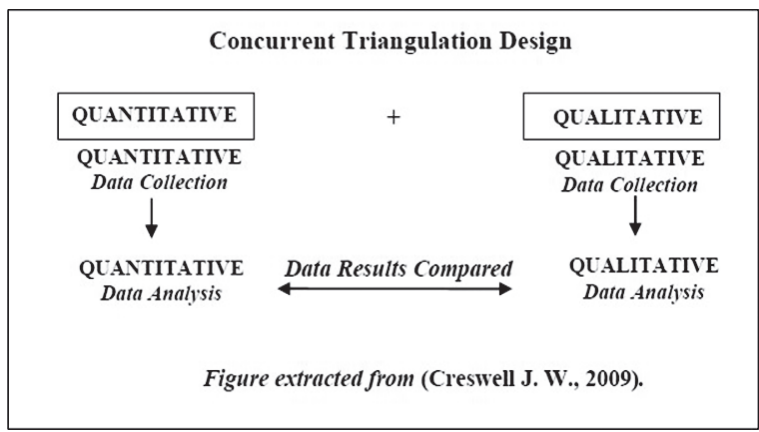

\section{Figure 2 : Concurrent Triangulation Design Selection of respondents}

The Thami Community is listed as one of the highly marginalized groups of people in Nepal. (NEFIN, 2017). It is also a community that largely depends on their indigenous knowledge for livelihood. Subsistence farming done in small landholdings is the primary occupation practiced through generations. Ninety percent of the farmers are totally dependent on rain-fed agriculture. The Thami people have deep traditional knowledge and experiences about agriculture which are reflected in the interviews.

A sample size of $100 \mathrm{HHs}$ was decided by taking into account the findings of the preliminary field visit, presence of maximum number of $\mathrm{HHs}$ in one clustered hamlet, difficulty in accessing other villages because of time and budget constraints. Moreover, Convenience Sampling Method was used during the field work. Firstly, a consultation with a key informant was conducted during the preliminary field visit. Secondly, a number of FGDs were conducted followed by in-depth interviews with some key informants and local farmers. Finally, the $\mathrm{HH}$ survey of $100 \mathrm{HHs}$ was conducted to acquire the required data; one individual per $\mathrm{HH}$ was interviewed for the purpose.

Altogether, eight participants with specific experiences were interviewed. FGD was conducted with nine participants in Faselung, Ward No. 1 of Bhimeswor Municipality. A mixed group of people, both male and female, ranging from youngsters to oldsters participated in the FGDs. In particular, the discussions were focused around the topics of socio-economic condition of the village and climate change. Interviews were concentrated on central to narrative research, and provided an opportunity to understand and reflect their perceptions regarding climate change and adaptation to climate change. The FGDs helped to generate detailed data and information regarding the indigenous knowledge and practices of Thamis in the research site. Likewise, key informant interviews were essential to connect and interact with the local people of the study area, especially the village heads, elderly group of people and teachers. The HH-surveyquestionnaire contained closed ended queries, and the data was collected using the Kobo Toolbox, a survey tool available on the internet.

In course of qualitative data analysis, the processes of coding, categorizing, thematizing and meaning-making were followed kindly check the sentence.

\section{Results and discussion}

The farmers of the Topar and Lisapoto Villages follow both the traditional and modern agricultural practices. They cultivate their rain-fed terraced lands (locally called "Khet" and "Pakho Bari"). The farmers produce paddy, wheat, maize, millet as their major crops. Similarly, potato is a prime vegetable grown in both the villages. Besides, they grow tomatoes, chilli, cauliflower, cabbage, cucumber, kiwi fruit and guava as cash crops.

Most of the respondents were small landholders, practicing subsistence farming. Only a few $\mathrm{HHs}$ were reported to have irrigation facilities and the rest were fully dependent on rain-fed agriculture resulting in lower productivity; the productivity used to be also determined on the basis of the availability of chemical fertilizers and pesticides for particular farmers (GoN, 2007). The farmers perceived the changing climate through its impacts on their daily lives. Education and communication media played a vital role in shaping these perceptions through information dissemination.

\section{Climate change perceptions in Thami Community}

\section{Awareness of climate change}

Climate change although an old phenomenon, was a new concept for the Thami Community. They understood climate change as the change in 
temperature and short-term weather. They could not relate disasters to climate change. Instead, they related climate change to weather change. The farmers' perceptions concerning climate change were mainly based on their indigenous knowledge. Besides, their perceptions were also found to have depended on awareness and non-formal trainings held in the villages. The Thamis use their own local terminologies for local climatic and weather phenomenon. However, they fully do not understand that the alterations in the climatic conditions are the causes of many environmental incidents such as erratic rainfall and droughts in the village (NHMRCC, 2015)

\section{Impacts of climate change on water}

Seventy eight percent of the respondents experienced the decrease in the amount of rainfall in the month of March as compared to the past kindly check the sentence. The respondents also experienced severe droughts in the months of April and May. Rainfall was perceived to be unpredictable and erratic for the rest of the months. Sixteen percent of the respondents who replied that there was no water scarcity were the ones with year-round access to water for irrigation.

\section{Changes in temperature (maximum and minimum)}

The respondents perceived increase in temperature which according to them has led to increase in production of new kinds of fruits and vegetables in their villages. Most of the respondents replied that temperature had increased during the last decade, which coincided with the official scientific data.

Figure 3 shows the maximum temperature to be in increasing trend during the period of 19872016 at the Jiri Meteorological Station. Each node in the figure represents a year. The standard deviation over the years has shifted upwards, which indicates the rise in average maximum temperature in the area for the past decades. Majority of the respondents also reported that they experienced warmer temperatures even in the colder months nowadays.

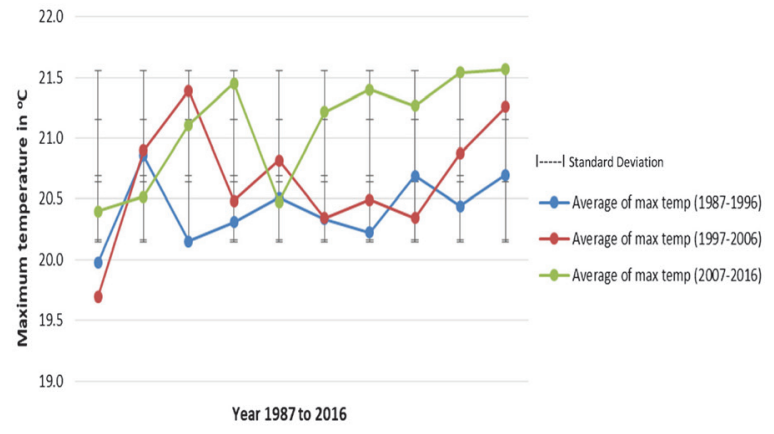

Figure 3 : Average maximum temperature at the Jiri Meteorological Station during the period of 1987-2016

Figure 4 represents the average minimum temperature through three decades. The chart shows the changes throughout the decades in average minimum temperatures with increased variability in the temperatures. The minimum temperatures in the past decade have gone upward by almost one degree Celsius. This result coincides with the perceptions of most of the respondents in the study site. Due to such rise in temperature, numerous extreme weather events were reported to be experienced by the respondents in the area. The direct impacts due to increasing temperatures are reduced crop yield, erratic rainfall, increased pests and diseases, landslides and droughts in the study area.

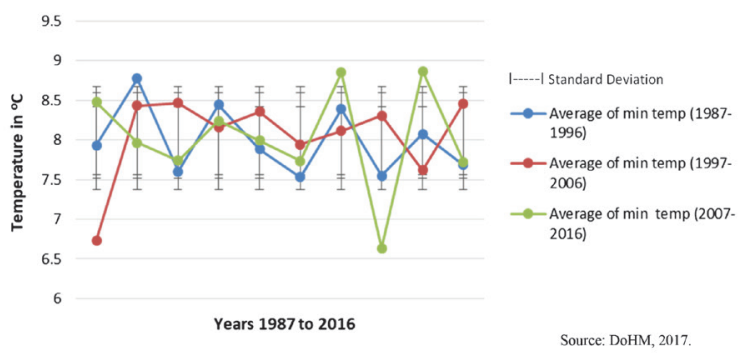

Figure 4: Average minimum temperature at the Jiri Meteorological Station during the period of 1987-2016

\section{Erratic rainfall}

The Thami farmers believed that incidences of droughts and floods in the village were due to "God's play" and nothing new. According to their elders, the rain clouds came in with the cold eastern winds and with the flowering of wheat or with the corn silk. As per the calendar, 
there should be regular incidences of rain arriving at mid-June instead of May. However, the farmers experienced heavy rainfall mostly accompanied by hail storms at the wrong time nowadays.

Figure 5 represents the average monthly rainfall data from the Jiri Hydrological Station from 1987 to 2016, which shows the changing characteristics of rainfall over time. The average rainfall during the period of 2007-2016 and 1997-2006 periods seems erratic than during the period of 1987-1996. Some Thami farmers also perceived the decrease in rainfall by observing the local stream named "Kuthali Khola" which has not risen nowadays as compared to the past. They also reported that erratic rain had now affected the production of maize, one of the staple crops. Likewise, the melting of snow was rapid at higher altitudes in most winters nowadays, which was an unusual occurrence in the past. In the past, the arrival of winter was indicated by the snowfall on the nearby hill, which also indicated the end of monsoon rain. Now, the farmers rarely noticed snow on that hill. Likewise in the past, the sowing time for wheat was indicated by the flowering of Prunus cerasoides (Paiyun). Similalry, the flowering of Michalia champaca (Champ) indicated the sowing season for maize and the presence of Demoiselle crane (Karang Kurung) indicated the season for sowing cucumber and summer fruits. These incidences made the indigenous knowledge useless in some situations.

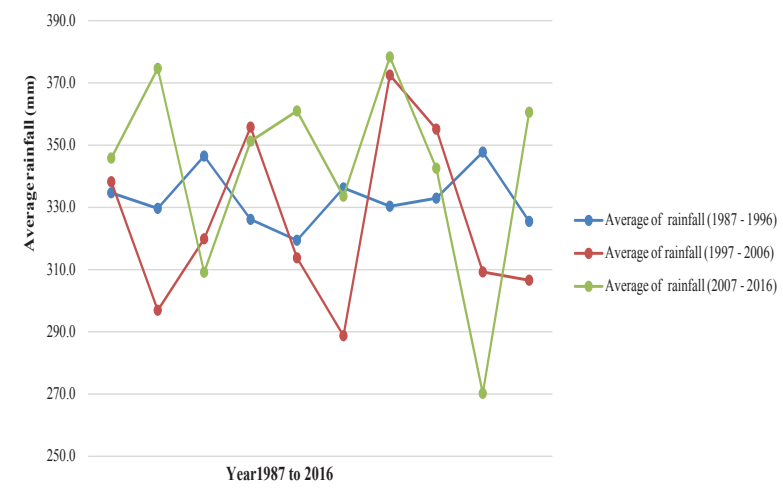

Source : DoHM, 2017.

Figure 5 : Average rainfall at the Jiri Meteorological Station during the period of 1987-2016

\section{Climate change impacts on agriculture}

Eighty five percent Thami respondents reported that agriculture sector was most affected by climate change. Similarly, 63\% respondents indicated the impact of climate change on the availability of water for agriculture in the village. Agriculture being a climate-dependent sector, is most vulnerable to climatic hazards. High dependency on agriculture for livelihood makes the Thamis susceptible to climate change. This also had implications on their socio-economic aspects, such as poverty, food insecurity and outmigration from the villages.

The cases of crop failures due to hail storm and droughts were more likely in the study site. According to the respondents, there was no rain in during the period of April-July because of which nothing grew during the months of October, November and December. In winter season, there were mostly no crops grown. There was also rise in pests and insects in the fields due to rising temperature. Besides, the loss of fertility in the soil was also caused by excessive use of chemical fertilizers and pesticides by the villagers to tackle low agricultural productivity. Further, the villagers had experienced the problems like discoloration of the crops and vegetables. Due to excessive use of chemical fertilizers and pesticides, most of the local breed of vegetables such as local spinach, cucumber and pumpkin had disappeared which has serious implications on the livelihood of the Thamis.

\section{Adaption practices \\ Change in agricultural practices as adaptation}

The Thamis were found to be applying different adaptation practices for climate change. Most of these practices were based on their indigenous knowledge while some were done with the support of different governmental and non-governmental programs. For seasonal calendar shifts due to climate change, the Thamis had to change crop plantation timings. The villagers were also found to be experimenting with hybrids and improved seeds from the local market for faster and larger quantities of production. They mostly used hybrid seeds for vegetables and for staple crops mostly in the case of insufficient home stored seeds. However, most of the Thami farmers were not aware of the quality of the seeds available in 
the market. Hybrid species needed proper care and use of modern tools and techniques and manuring for better growth. Some of the offseason species even grew all year round. Though the Thami farmers had shifted to cultivating new seeds for greater yield, they complained about loss of nutritional values and taste in their new productions. Thamis were also given trainings by various organizations on modern agricultural practices which are beneficial and had created lucrative business opportunities of vegetable farming.

\section{Adaptation to erratic rainfall and droughts}

\section{i. Conservation of forest and water source management}

Each of the HHs at the Topar and Lisapoto Villages possessed taps installed with the support of the local government and Nepal Red Cross. Another way the Thamis were adapting to erratic rainfall was by conserving forest and planting perennial plants around the water springs to help conserve the water sources. During drought seasons, they had a system of water source management through water pooling and using water from the streams. This sometimes resulted in conflicts between the farmers as there were no systems for measuring the volume of water used per HH. They also used drought-resistant crops provided by the District Agricultural Office at Charikot. Some Thamis did not cultivate anything at this time of the year whereas some of them had developed irrigation channels.

\section{ii. Early harvesting as adaptation}

In the case of hailstorm, some of the farmers tried to predict it by observing the changing weather (thundering and lightning). There was nothing that the villagers could do to stop the effects of hail storm than to prevent the crops from getting affected which could be done by early harvesting. This could be done only when the crops were almost ripe. Same was the case for less rain and drought. Also if there was more rain than required, they had a traditional draining system.

\section{iii. Use of modern technology}

Likewise, drip irrigation and water pooling techniques practiced by the Thamis was for efficient water use in the field. In the case of late seasonal rainfall, the crops were sowed a month later than scheduled. In the winter when temperatures lowered, they planted cold- resistant crops, such as wheat, buckwheat, paddy, maize and cabbage. Some farmers also used plastic tunnels for farming tomatoes in winter.

\section{Adaptation to increasing insect pests by use of home-made pesticides and fertilizers}

Thamis used to sprinkle homemade pesticides/ repellant on their plants, which were prepared by adding tobacco in urine (of both human and cattle) and adding water to dilute the mixtures. This practice was helpful in chasing away the pests, especially the red ants. Apart from this, the farmers also made use of Artimisia vulgaris (Titepate) and the leaves of Zanthoxylum armatum (Timmur) in this mixture. These indigenous ways of keeping the pests away were found to be very useful in every step of the plant growth. The use of market pesticides, moreover, affected the plants, humans and animal health. However, the farmers used chemical pesticide called "Bevestine" by mixing it with the seeds before sowing when the homemade pesticides stopped working.

\section{Adaptation to other climate-induced hazards by use of bio-engineering and plantation of new hardy crop species}

In the case of soil erosions and landslide, the Thamis used big stones to reinforce the terraced walls of the fields. Also, most of the Thamis applied their knowledge about elevation and other traditional farming techniques, such as making barriers for guiding the water in their fields, which had helped them manage and regulate water around their fields. Likewise, the villagers also adapted to increasing temperature by planting new varieties of crops and vegetables. The local government also conducted trainings and awareness programs in the villages on integrating traditional and modern ways of farming. They were also provided with seed bins and technical support for local seed production. Furthermore, they were also supported with tractors, plastics for ponds, rainwater harvesting, and drip irrigation by different Non-governmental Organizations (NGOs) and International Non-governmental Organizations (INGOs). 


\section{Migration}

Purchasing food from the market is another adaptation measure done by the Thamis when there is not enough production of food grains in their fields to sustain for the entire year. The data from the $\mathrm{HH}$ survey indicated that only $6 \%$ respondents had an adequate amount of food grains for 12 months whereas the rest purchased food grains from the market and migrating to the cities and working as labor for rest of the year.

\section{Conclusion}

Indigenous communities are the most vulnerable to climate change. They are among the first to face its direct consequences due to their dependence and close relationship with nature. Climate change had severely affected agriculture in the research sites, posing threats to food security. Nevertheless, there was increased productivity in some areas due to increase in temperatures. However, some were concerned about the change in traditional species of plant species. Their traditional ways of farming was threatened due to climate change. Although short-term adaptation practices were carried out in the villages, they did not possess any additional financial sources to face the long-term challenges caused by climate change. Further, there was an increased interest in modern technology in farming.

Although this study is limited to a small geographical area, it reflects on a much bigger problem faced by many farmers in the hilly regions of Nepal. This problem needs intervention at much larger scale by the government through proper planning and policies for environment management, climate change adaptation and mitigation, especially in agriculture and water sectors.

\section{References}

Arbuckle, J. G., Morton, L. W. and Hobbs, J. 2015. Understanding farmers' perception on climate change adaptation and mitigation : The roles of trust in sources of climate information, climate change beliefs and perceived risk. SAGE Publications Inc.

Creswell, J. W. (2009). Research design : Qualitative, quantitative and mixed method approaches. SAGE Publications Inc, Los Angeles.

GoN. 2007. Household survey of Dolakha Suspachhyamawati region. Government of Nepal.

MoSTE. 2015. Indigenous and Local Knowledge and Practices for Climate Resilience in Nepal. Ministry of Science, Technology and Environment, Kathmandu, Nepal.

GoN. 2017. Historical, Religious and Cultural Heritage, Nature and Tourism Enriched Bhimeshwor. Office of the Municipal Executive, Bhimeshwor Municipality, Government of Nepal. http : //bhimeshwormun. gov. np/en/node/4 (accessed on $6^{\text {th }}$ Sep, 2017).

Maplecroft, V. 2011. Risk calculators and dashboards. https : //maplecroft. com/about/ news/ ccvi. html (accessed on $7^{\text {th }}$ July, 2017).

MoAC. 2011. Climate Change Adaptation and Disaster Risk Management in Agriculture Priority Framework for Action 2011-2020. Ministry of Agriculture and Cooperatives, Kathmandu, Nepal.

NAPA/MoPE. 2010. Thematic working group summary report. National Adaptation Program of Action/ Ministry of Population and Environment, Kathmandu, Nepal.

NEFIN. 2017. Categorization of indigenous people based on development. Nepal Federation of Indigenous Nationalities. http : //www. nefin. org. np/list/ Categorization-of-Indigenous-Peoplebased-ondevelopment-/5/95/6 (accessed on $7^{\text {th }}$ July, 2017).

DoHM. 2015. Study of climate and climatic variation over Nepal. Department of Hydrology and Meteorology, Kathmandu, Nepal.

Pachauri, R. K., Meyer, L. A. and Team, T. C. 2014. Climate Change 2014 : Synthesis Report. Contribution of Working Groups I, II and III to Fifth Assessment Report of the Intergovernmental Panel on Climate Change. Geneva, Switzerland. 